\section{LAS SOMBRAS DE ALEIXANDRE Y CERNUDA EN LA POESÍA DE FRANCISCO UMBRAL}

\author{
Marina Casado Hernández \\ Universidad Complutense de Madrid \\ Marina.casado.hernandez@gmail.com
}

\section{ALEIXANDRE'S AND CERNUDA'S SHADOWS AT FRANCISCO UMBRAL'S POETRY}

Cómo citar este artículo/Citation: Casado Hernández, M. (2015). "Las sombras de Aleixandre y Cernuda en la poesía de Francisco Umbral". Arbor, 191 (774): a246. doi: http://dx.doi. org/10.3989/arbor.2015.774n4001
Copyright: (C) 2015 CSIC. Este es un artículo de acceso abierto distribuido bajo los términos de la licencia Creative Commons Attribution-Non Commercial (by-nc) Spain 3.0.
RESUMEN: Francisco Umbral fue un poeta tardío: no publicó su primera obra poética hasta 1981. En su poesía, puede apreciarse especialmente la influencia de dos miembros de la Generación del 27: Vicente Aleixandre y Luis Cernuda, que se acogieron a la vertiente más formalista de su generación, rechazando la popular. Además, ambos se caracterizan por imprimir narratividad a su poesía, un rasgo que también hallamos en la de Umbral. La huella más visible de Aleixandre en la obra poética umbraliana es, sin duda, la constante metaforización. La perspectiva de "pesimismo crónico", el spleen que envuelve los versos, es influencia de Cernuda. El presente trabajo analiza el vínculo entre un poema de Vicente Aleixandre, "Hija de la mar", y otro de Umbral, "Herramienta del mar", relacionando ambos con los personajes que habitan la poesía y la narrativa de Cernuda. Además, en los tres hallamos una relación entre el amor y la muerte.

PALABRAS CLAVE: poesía; influencia; metáforas; pesimismo; mar; inocencia; amor; muerte.
ABSTRACT: Francisco Umbral began late as a poet, not publishing his first poetic works until 1981 . We can particularly see the influence of two members of Generation of ' 27 in his poetry: Vicente Aleixandre and Luis Cernuda, who represent the more formal aspect of their generation, having eschewed the more popular facet. They are characterised by narrative poetry, which is also a feature of Umbral's poetry. The most notable influence of Aleixandre is the constant use of metaphors. The perspective of "chronic pessimism", the spleen that we find in his verses, are an influence of Cernuda. This study examines the link between an Aleixandre's poem, "Hija de la mar", and a Umbral's poem, "Herramienta del mar", and it relates both poems with the characters who live in Cernuda's poetry and prose fiction. We can also find a link between love and death in the three poets.

KEYWORDS: poetry; influence; metaphors; pessimism; sea; innocence; love; death. 


\section{VOCACIÓN NARRATIVA Y PRESENCIA DE LA GENE- RACIÓN DEL 27}

Umbral no publicó su primera obra poética hasta 1981. Se trata de Crímenes y baladas. Antología de prosas líricas, una colección de poemas, la mayoría de ellos en prosa, que bien pudieran ser pequeños relatos, debido a su carácter marcadamente narrativo, generador de historias. En el prólogo a la Obra poética (1981-2001) de Umbral, Miguel García-Posada interpreta así esta convergencia entre lírica y narrativa:

Él no se consideraba poeta profesional, aunque se estimaba y valoraba como prosista, no tenía en gran aprecio su obra poética [...]. La prosa [...] fue la gran arma que le dio la vida para hacerle frente; la poesía no le había servido para eso [...]. Pero fue decisiva en la constitución de su estilo.

[...] Sin lo poético, su prosa -su estilo, en definitivahabría sido muy otro; es lo poético lo que le da el toque especial, la nota distintiva que la identifica como prosa autorial (Umbral, 2009, pp. 21-22).

La poetización, según García-Posada, se encuentra presente en toda la obra de Umbral, no sólo en la poética, y en la práctica se traduce como el uso constante de acertadas metáforas. Por tanto, aunque Umbral no publicase su primera obra de poesía hasta 1981, se puede afirmar que esta ya se encontraba presente desde siempre.

Esta convergencia umbraliana que poetiza su prosa también prosifica su poesía, sobre todo la de su primera obra, Crímenes y baladas. En cada poema, asistimos como lectores al despliegue de una historia independiente, o continuada, como ocurre con el personaje ficticio de Leticia/Lutecia, que protagoniza numerosas de las composiciones de este primer libro, permitiéndonos conocerla "por capítulos".

García-Posada atribuye la poetización de su prosa a la influencia que sobre él ejerce la obra de Marcel Proust, que a su vez derivaría de la intersección entre Chateaubriand, Ruskin y Baudelaire. En cuanto a su verso, afirma el crítico que procede de Juan Ramón y de los poetas del 27 y Neruda. Profundizando en este punto, hemos de atender a lo que el propio Francisco Umbral dijo acerca de Vicente Aleixandre, su más adorado poeta de la Generación del 27: "Aleixandre nunca abandonó, hasta última hora (deben descontársele los libros de la vejez) el tono narrativo, lo que le mantiene vivo y fresco" (Umbral, 1994, p. 180). Y aunque no tan admirado -al menos, en apariencia-, Luis Cernuda también le suscitó las siguientes palabras: "Sólo quiere dar un verso de pensamiento, una prosa de acento poético donde se elucida la experiencia de la vida" (Umbral, 1994, p. 180).

Vicente Aleixandre y Luis Cernuda destacan, dentro de su generación poética, por rechazar la vertiente popular que tanto atrajo a otros poetas de su tiempo, como Lorca o Alberti, y decantarse más por el formalismo. A este respecto, conviene rescatar las palabras de García-Posada en el prólogo de Crímenes y baladas: "Umbral se adhería a la tradición más barroca, más formalista, de nuestra literatura; más Quevedo que Cervantes, más Miró que Baroja, más Darío que Clarín, más Valle que Azorín" (Umbral, 2009, p. 14). Ese culteranismo que se aprecia más visiblemente en la obra de Aleixandre y Cernuda, lo extiende Umbral a toda la Generación del 27:

La generación del 27 [...] tiene una acusada vocación minoritaria, cultista, y las excepciones dentro del grupo son contadas [...]: García Lorca el primero, en cierto modo Salinas (como poeta amatorio) y Alberti como poeta político.

Guillén o Aleixandre se mantienen tan virginales como el primer día (Umbral, 1994, p. 217).

A Guillén y Aleixandre Umbral tendría que sumarles, sin duda, a Cernuda, obsesionado con el rechazo a lo popular. Respecto a las excepciones que señala, García Lorca fue para él objeto de estudio, incluso escribió un ensayo dedicado por entero al granadino: Lorca, poeta maldito. De Rafael Alberti le quedó en su obra -sobre todo, en la de los últimos años- esa tendencia a dedicar poemas a personalidades -amigos, artistas, políticos-, ensalzándolos o describiéndolos, simplemente. De Alberti rechaza la faceta de poeta social. Y es que Umbral nunca fue favorable a este tipo de poesía, llegando hasta el punto de llamar "un recitador, más que un poeta" a León Felipe.

A pesar de que en la obra umbraliana apreciamos, en mayor o menor medida, el rastro de casi todo el 27, en este trabajo me he centrado en analizar, la huella concreta de Aleixandre y Cernuda destacando distintos aspectos -como el carácter narrativo ya citado- en los que las poéticas coinciden, incluso poemas determinados de Umbral que recuerdan inevitablemente a alguno de la obra alexandrina o cernudiana.

\section{LA VISIÓN UMBRALIANA DE ALEIXANDRE Y CERNUDA}

Francisco Umbral leyó las obras de Vicente Aleixandre y Luis Cernuda siendo muy joven. En novelas y ensayos repite la anécdota de que, durante un viaje con amigos a Londres, se encontró en la casa donde 
vivía Cernuda, pero que él poeta se negó a recibirlos. A Aleixandre sí llegó a conocerlo y a establecer con él una relación de amistad.

Fue la apertura al mundo y a la luz para nuestra adolescencia sombría. [...] Era la altura, el deslumbramiento, la luz, la pasión, el paraíso sin sombra, todo eso que el adolescente sabe que está en algún sitio y no lo encuentra (Umbral, 1994, p. 175).

Así describe a Umbral a Vicente Aleixandre en el capítulo que le dedica dentro de su colección de artículos y ensayos Las palabras de la tribu. Mientras para todos los demás escritores -de varias generacionesque desfilan por las páginas de este libro tiene palabras críticas, o de reserva, en el caso de Aleixandre su valoración es absolutamente positiva. Aleixandre era, para Umbral, un faro en la oscuridad de la dictadura franquista, un paréntesis de luz, un refugio de auténtica poesía. Un ser elevado que, sin embargo, gustaba de vivir entre los hombres. En sus propias palabras: "la máxima luz, la luz toda de la poesía" (1994, p. 152). De él destaca, por encima de todo, la pasión por la vida, su dedicación absoluta a la poesía, su alejamiento consciente de cualquier tipo de ideologización, como si viviera en una dimensión atemporal, exclusivamente poética. La Naturaleza presente en los poemas de Aleixandre es, muchas veces, una Naturaleza intuida o soñada, debido a la condición de enfermo crónico del poeta, obligado a un reposo constante. Pero esto, para Umbral, no constituye una limitación, sino al contrario: eleva aún más la consideración que de él tiene.

La huella más visible de Vicente Aleixandre en la obra poética umbraliana es, sin duda, la constante metaforización. Dice Umbral: "Su primer libro, éste, Pasión de la tierra, lo leí de muy joven, encontrando que estaba entre la greguería y el surrealismo: "Las viejas respiran por sus encajes»" (1994, p. 175). La poesía umbraliana también se encuentra plagada de metáforas que casi podrían considerarse greguerías -teniendo en cuenta la importancia que atribuía Umbral, en cuanto a influencia, a Ramón Gómez de la Serna-, hasta el punto de que existen poemas que constituyen una sucesión de imágenes precisas e ingeniosas, como "La lluvia":

\footnotetext{
La lluvia es un paraguas

que perdió las varillas,

la lluvia es un caballo

que se escapa en la noche,

la lluvia va desnuda,
}

es la loca del pueblo,

y lleva en la cabeza las coronas de agua que trae la primavera a los dioses en seco.

(2009, p. 142)

Precisamente, la ausencia de metaforización es la crítica más importante que Francisco Umbral realiza a la obra de Luis Cernuda: "Cernuda decide suprimir la metáfora, pero la sustituye por algo peor: un énfasis, un punto de vista del poeta [...]. Ejerce un misoneísmo difícil de aguantar" (1994, p. 180). Umbral, al igual que Aleixandre, prefiere sugerir al lector que sentar cátedra.

Umbral siempre fue muy crítico con la persona de Cernuda, atribuyendo gran parte de su fama a la valentía a la hora de declarar su homosexualidad en su obra, y llegando a afirmar que "Cernuda era gran poeta y mala persona" (1994, p. 182).

Sin embargo, y a pesar de sus reservas, se aprecia influencia de Cernuda en la obra poética de Umbral, incluso a simple vista, si solo hojeamos los títulos -no cabe duda de que al escribir "Preludio para un cuerpo", Umbral pensó de manera consciente o inconsciente en los "Poemas para un cuerpo" del sevillano-. Lo más evidente es ese spleen cernudiano, vinculado a un pesimismo crónico, a una desesperanza, a un cansancio que envuelve la poética de uno y otro -radicalmente contrario a la pasión, incluso la euforia, exhibida por Aleixandre-. En el caso de Umbral, el fallecimiento de su hijo a los cinco años -tras una dolorosa y larga enfermedad- dejó en él un poso de amargura y una permanente tendencia a la contemplación de la muerte como algo cercano, siempre presente.

Pero esa perspectiva pesimista la encontramos en Umbral incluso antes del fallecimiento de su hijo. Relacionado con esto, en su biografía, Anna Caballé refiere una curiosa anécdota ocurrida en 1950, en la juventud del escritor. Durante un recital poético celebrado en el Teatro Carrión de Valladolid, Umbral:

Leyó con su voz enfática: "Estoy cansado..., estoy cansado..., estoy cansado..., estoy cansado". Lo repitió un montón de veces. Después salió del escenario con [...] solemnidad.

Hay un poema de Luis Cernuda titulado "Estoy cansado" que pudo darle la idea. Forma parte de su libro Un río, un amor, publicado en 1929 (Caballé, 2004, p. 111).

Esta anécdota nos plantea la cuestión de hasta qué punto era consciente Umbral de la influencia que sobre él ejerció la obra de Cernuda, y la pregunta de por qué se mostraba tan escéptico ante esa idea. 


\section{COSMOVISIÓN Y PERSONIFICACIÓN DE LA NATU- RALEZA. MAR E INOCENCIA}

Umbral concebía a Vicente Aleixandre como un "poeta cósmico", es decir, que usaba en su poesía el método deductivo: de lo universal -la Naturaleza- a lo particular -su propia condición humana, con sus sentimientos y emociones-. En palabras del propio Umbral: "El primer impulso en el poeta [...] es un impulso hacia el universo [...]. Y luego, vuelto a sus límites humanos, necesita hacer su pasión practicable, referirla a alguien, a una persona" (1994, p. 178).

Para Umbral, al actuar así Aleixandre "se sentía universo", parte de la Naturaleza. Esta huella aleixandrina la podemos apreciar en los poemas de Umbral que hacen alusión a elementos naturales como el mar, la lluvia, la tormenta. Afirma que "la lluvia es algo que nos pasa y se parece a la tristeza" (2009, p. 144). Al interpretar la lluvia como un estado de ánimo lo que persigue Umbral es sentirse parte del universo. Al igual que en "Herramienta del mar" y "Herramienta del aire", el ser humano se concibe como objeto de la Naturaleza y no al contrario: no es la Naturaleza la que se pone al servicio de lo humano.

Precisamente el poema "Herramienta del mar" (Umbral, 2009, p. 37), guarda una gran similitud con "Hija de la mar" (Aleixandre, 2005, p. 407), incluido en la obra aleixandrina La destrucción o el amor. Ambos poemas describen a una mujer joven que permanece tendida, sola, en la orilla; una mujer que pertenece al mar-Aleixandre la llama "hija" y Umbral "herramienta"-. Desde los primeros versos, la idea es la misma: "Muchacha, corazón o sonrisa, / caliente nudo de presencia en el día", comienza el poema de Aleixandre. "La muchacha en su playa, en su luz matutina", arranca el de Umbral. Observamos que la palabra "muchacha" se repite en ambos, así como la vinculación con la mañana -"en el día", "luz matutina"-. Esta joven protagonista marina es el símbolo de la inocencia. Aleixandre lo expresa claramente en sus versos: "Tu inocencia como un mar en que vives", "No mientas nunca, conserva siempre / tu inerte y armoniosa fiebre que no resiste"; mientras que Umbral alude a que ella está dormida, es decir, vulnerable e inerte: inocente. La quietud que invade al personaje umbraliano, por el que "pasan tiempos y pasan sueños" es la misma inercia mencionada que domina al de Aleixandre; inercia que se identifica con la Naturaleza, que permanece sobre la efímera existencia de los hombres.

El desnudo, otro símbolo de la inocencia-relacionado en la Biblia con el estado natural de la mujer antes de su expulsión del Paraíso- se produce también en ambos casos, así como el color de la pureza: el azul -la niña de Aleixandre tiene los ojos azules, y Umbral menciona que son "los azules del tiempo" los que configuran a la suya-. El cuerpo, en los dos poemas, se encuentra tendido, y también hallamos similitudes en su descripción -Aleixandre lo describe "dorado", y Umbral habla de su "vientre dorado"-.

Los dos poemas hacen referencia a un estado de inocencia inicial, que en Umbral se vincula con el mito bíblico de Eva, la primera mujer, cuando dice: "Siempre ese mito leve, esa chica primera". Aleixandre no llega a tanto y se queda, simplemente, en relacionar a su muchacha con una personificación de la Naturaleza. Sin embargo, las protagonistas de uno y otro poema aparecen asociadas a una idea de pureza, de virginidad, igual que esa primera mujer del mito bíblico. La de Aleixandre es una "irresponsable belleza que a sí misma se ignora", "sola isla aún intacta"; Umbral habla de "su sexo nocturno como enigma en la luz". La palabra "enigma" se ha de interpretar en este caso como algo que todavía permanece intangible, aunque no inalcanzable.

En los dos poemas, ese estado de inocencia parece fácil de romperse. La muchacha de Aleixandre posee "un desnudo dócil a su tacto", pero el poeta se recrea en el bienestar producido por su mera contemplación, sin barajar la idea de tocarla. Los versos de Umbral, por el contrario, proyectan unida a esa calma una cierta ansiedad, que nos hacen pensar que la quietud, la inocencia, se quebrará de manera inminente: "sexo despierto", "fresca esperanza", "pálida expectativa", "lo disponible, lúcido y femenino". Y en uno de sus últimos versos, Umbral especifica más ese momento: "cuando todavía el mundo tiembla de expectativas".

La muchacha marina de Umbral podría interpretarse como una proyección de la de Aleixandre, avanzado el tiempo, a punto ya de marchitarse su inocencia.

En la obra de Luis Cernuda, también hallamos la presencia de criaturas fuertemente vinculadas al mar, que toman identidad masculina -debido a su homoerotismo-, al contrario que en Aleixandre y Umbral. En Cernuda, es la figura del marino la que se identifica con el mar o con algo perteneciente a él, además de asociarse con la idea de sensualidad. En el relato "El indolente" -que casi podríamos calificar de prosa poética-, asistimos a la aparición de una de estas criaturas marinas tan frecuentes en la obra cernudiana, un joven pescador, Aire:

Miré al islote de la Pena Muerta. Vi su fortaleza en ruinas bajo la luz dorada de la mañana. [...] 
Entonces surgió una aparición. Al menos por tal la tuve, porque no parecía criatura de las que vemos a diario, sino emanación o encarnación viva de la tierra que yo estaba contemplando.

Aquella criatura, fuese quien fuese, saltando desnuda entre las peñas, con agilidad de elemento y no de persona humana, se fue acercando poco a poco. Así conocí a Aire.

[...] Había en su pelo esas vetas más claras de la concha llamada carey, tonalidad que denota larga familiaridad con el mar. Su cuerpo me apareció aquella mañana sobre el cielo, fino, resistente y esbelto, tal modelado por las olas, que entienden de eso como escultor ninguno ha habido en la tierra (Cernuda, 2002, p. 280).

En este fragmento se observan elementos comunes a los respectivos poemas de Aleixandre y Umbral, como la playa, la mañana, el color dorado -en esta ocasión, en la luz-, el desnudo, la familiaridad del muchacho con el mar, hasta el punto de parecerle al narrador que forma parte de él, o que han sido las olas las que lo han "modelado". Aire podría ser un "hijo de la mar". La principal distinción entre este personaje masculino y los dos femeninos anteriores es que este se encuentra en movimiento, saltando, acercándose. Cernuda no se limita a la contemplación, ni siquiera a la contemplación ansiosa, sino que entra en interacción con esa Naturaleza personificada. Tal vez por eso, simbólicamente, después de que el narrador trate de "domesticar" a Aire, culturizándole y alejándolo de su estado salvaje natural, el muchacho acaba muriendo en el mar, como si el mar lo reclamase.

Lo que en Aleixandre y Umbral es una muchacha, una niña, en Cernuda es un marino. Los marinos, en su obra, cobran un aspecto angelical, atributos similares a los de las muchachas: "Los músculos dorados del marino" (Cernuda, 2005, p. 189).

Los siguientes versos del poema cernudiano "A un muchacho andaluz" hablan, en correspondencia con el de Umbral, de "forma primera": "¿Eras emanación del mar cercano? / Eras el mar aún más / Que las aguas henchidas con su aliento, / [...] Eras forma primera, / Eras fuerza inconsciente de su propia hermosura (Cernuda, 2005, p. 221). Esa "fuerza inconsciente de su propia hermosura" es la misma "irresponsable belleza que a sí misma se ignora" que hallábamos en los versos de Aleixandre.

Y la posición tendida de la muchacha dormida en la orilla, ajena aún al deseo, la descubrimos también en Cernuda en el poema "El joven marino":
"A lo largo de tantas lentas mañanas, ganadas en ocio celeste,

[...] De reposo divino, divina indiferencia;

Caído el cuerpo flexible y seguro, como un arma mortal,

Ante la gran criatura enigmática, el mar inexpresable,

Sin deseo ni pena, igual a un dios" (Cernuda, 2005, p. 238).

Sin duda, Umbral bebió de ambas fuentes -Aleixandre y Cernuda- para escribir "Herramienta del mar". También para formar su concepción de la Naturaleza como algo ajeno al hombre y más poderoso, más vasto que el mero existir humano.

\section{LA CONCEPCIÓN ALADA DEL AMOR. EROS Y TÁNATOS}

La obra poética umbraliana concibe el amor como sexualidad. Él mismo lo especifica en un poema cuando dice, refiriéndose al sexo: "Lo llamamos amor porque nos turba" (2009, p. 200). Y unos versos más adelante: "Es la vuelta de las especies, / la hermosa zoología de nuestras vidas". Por tanto, para Umbral las relaciones sexuales son el regreso a la animalidad que aún pervive en los seres humanos, la vía mediante la cual estos pueden volver a sentirse parte de la Naturaleza, como un elemento más, en la línea propugnada por Vicente Aleixandre.

En "Lo ciego" (2009, p. 39), Umbral alude a esta animalidad del encuentro sexual en la que se acalla la conciencia: "Los amantes sin rostro son sólo cuerpo ciego, humanidad violenta". En ese instante que él describe como "ciego": "Están ya muy altos, altos los dos amantes, en la carrera ciega, tropeles hacia el cielo". La analogía con el cielo se repite en "Indeleble" (2009, p. 41), donde habla de "la presencia de un cielo más profundo y más negro" que se identifica con el sexo femenino. En "Vencidos" (2009, p. 38), Umbral describe la situación posterior a un encuentro sexual: "Vencidos los amantes, vencidos, caminantes; direcciones contrarias, alejarse, encontrarse: iban uno hacia otro, daban miedo al silencio, iban hacia el encuentro: se han perdido en el cielo". Es decir, que una vez alcanzado el cielo, cuando todo termina, se dispersan allí: se pierden en medio del silencio.

Existe un poema de Vicente Aleixandre, incluido en La destrucción y el amor, titulado "La luz", en el que también mezcla las ideas de amor, cielo y silencio:

¡Ay amorosa cadencia de los mundos remotos, de los amantes que nunca dicen sus sufrimientos, de los cuerpos que existen, de las almas que existen, de los cielos infinitos que nos llegan con su silencio! (Aleixandre, 2005, p. 362) 
En este caso, el adjetivo "infinitos" ha de interpretarse como sinónimo de desolación, de corrupción de ese cielo alcanzado a través del amor y arrasado por el silencio, por la incomunicación. Un cielo donde es fácil perderse, como les ocurre a los amantes de Umbral.

La concepción alada del sexo, o del amor, la encontramos también en la poética de Luis Cernuda. "Si el amor fuera un ala", llega a decir Cernuda. En su obra Donde habite el olvido, escrita tras un romance frustrado, describe el amor como un "Afán que en otro tiempo levantaba / Hasta las nubes sus olas melancólicas". En estos versos, además, Cernuda identifica el amor con el mar, con el agua, algo que ocurre a lo largo de toda su obra. Volvamos de nuevo al poema umbraliano "Vencidos", donde leemos: "Vencidos, los amantes, son un río que pasa, son un lago que queda, una pura ensenada. Vencidos, los amantes, son un mar que regresa". En Umbral, igual que en Cernuda, el final de un amor es agua en calma, lo que antes había sido olas y tempestades que ascendían.

En ese mismo poema, "Vencidos", Francisco Umbral termina diciendo: "Qué silencio de espada". La espada aquí simboliza la muerte, el final repentino de la vida, que llega cuando termina el encuentro sexual, la comunicación mágica entre los amantes. Para Umbral, el amor -o el sexo- se encuentra íntimamente ligado a la muerte. "Si la muerte es pregunta, el sexo es la respuesta", dirá. El sexo se concibe así como una vía de escape de la muerte. Pero en Umbral, el sexo resulta efímero, fugaz: aparece ensombrecido por un pesimismo que transforma al yo poético en un ser insatisfecho, abocado a la espera, a la soledad.

Esta dimensión pesimista no se corresponde con la perspectiva de Aleixandre, cuyos poemas amorosos expresan una dicha imparable, eterna. En Aleixandre, el amor es destrucción, muerte, pero se trata de una muerte dulce y añorada, porque es terminar con la propia vida para vivir dentro del ser amado: “Quiero amor o la muerte, quiero morir del todo, / quiero ser tú, tu sangre, esa lava rugiente" (2005, p. 362).

En este sentido, la poética de Umbral se encuentra más vinculada a la de Luis Cernuda, con el que comparte ese sentimiento de pesimismo que parece sobrevolar incluso los momentos de mayor entrega amorosa. Así ocurre, por ejemplo, en los versos que dicen "Qué ruido tan triste / el que hacen dos cuerpos cuando se aman". Al igual que para Umbral, para Cernuda "Mentira, amor, placer no son la muerte", pero sí conducen a ella al terminarse: "No es el amor quien muere, somos nosotros mismos". La muerte en Cernuda también debe interpretarse como algo negativo, al contrario que en Aleixandre, que la concibe como vía de mayor unión con el ser amado.

\section{BIBLIOGRAFÍA}

Aleixandre, V. (2005). Poesía Completa (ed. A. Duque Amusco). Madrid: Visor.

Caballé, A. (2004). Francisco Umbral. El frío de una vida. Madrid: Espasa Calpe.
Cernuda, L. (2002). Prosa II (ed. D. Harris y L. Maristany). Madrid: Siruela.

Cernuda, L. (2005). Poesía Completa (ed. D. Harris, D. y L. Maristany). Madrid: Siruela.
Umbral, F. (1994). Las palabras de la tribu. Barcelona: Planeta.

Umbral, F. (2009). Obra poética 1981-2001 (ed. M. García-Posada). Barcelona: Seix Barral. 